\title{
Simulation-based Prediction Model of the Auto-body Multi-Stage Forming Process
}

\author{
Dong-Guk Han ${ }^{1}$ and Dong-Won Jung ${ }^{2}$ \\ ${ }^{1}$ The Project Management Center Cultivating Smart Grid \& Clean Energy Manpower(CK-1), \\ 690-756, Republic of South Korea \\ ${ }^{2}$ Department of Mechanical Engineering, Jeju National University, 1 Ara 1-dong, Jeju-si, Jeju 690-756, Republic of South Korea
}

\begin{abstract}
Usually auto body need several forming stages in the real manufacturing. Every forming parameter within the process has a significant influece on the forming quality. A reasonable desgin of the stamping process is needed. According to statistics, stamping process cover auto parts account for a large proportion. The quality of autobody panel stamping forming not only affects the quality of vehicle assembly, vehicle appearance, but also affect the manufacturing cost of the car as well as the development cycle of new models. Auto body sheet metal forming parts compared with the genenral stamping forming process, the material is thinner, have a more complex spatial curved shape, large structure size, and higher forming quality requirements, so a pricious prediction is needed. This paper use the autoform sofeware to simulate the stamping process and predict the result. Through the simulation, the thickness and strain change are revealed, and the FLD will show the possible wrinkling and failure areas.
\end{abstract}

Keywords-numerical simulation; stamping, auto body; autoform

\section{INTRODUCTION}

The traditional auto body forming process design methods rely mainly on qualitative analysis and practical experience. In most cases, the forming process and process parameters can be determined through several tests. Or refer to similar parts of the prior materials, and according to the process of shaping and forming part of the analysis, develop a preliminary program of the process, and then again by rushing constantly revised forming process and process parameters or modify the shape of the mold to form the most reasonable technology program, which is an iterative development process, a long time and high cost [1-3]. With the development of industrialization, increasingly shorter product life cycles, new materials continue to use the traditional design methods have obviously not suited to the requirements of modern industrial development. In order to meet the needs of the automotive industry, providing high-quality auto body has become an important task of the car manufacturers. Stamping process, whether at the beginning or in the auto body manufacturing pre-production, it always plays a very important role.

In recent years, with the computer software and hardware technology's rapid development and cross and combine of computer technology, graphics and mechanics. Technology-based simulation in computer-aided engineering research has been widely applied in the sheet metal forming process. For complex shaped such as autobody forming process parts many universities and research institutes at home and abroad, are pay attension to it. And some reseraches achievements has played a significant role in guiding the actual production[4-6]. Currently in the industry, sheet metal forming process design in addition to relying on traditional qualitative analysis, physical simulation test and proven and other means, the numerical simulation, computer-aided design and even artificial intelligence technology research board metal forming process design has become mainstream.

Sergey F. study the influence of trimming conditions on quality of trimmed surface and to modify the trimming process to eliminate slivers and burrs from trimmed surface [7]. A.Andersson find a solution concerning the prediction of surface defects, a laboratory tool was manufactured and analysed both experimentally and numerically. Several different sheet materials were analysed in order to evaluate their sensitivityto surface defects, and to investigate the possibility to predict defects in different materials[7]. G.H. bae is concerned with a simulation-based predictionmodel constructed using the Box-Behnken design for sheetmetal forming processes to design the draw-bead. The shape

parameters such as the bead height, the shoulder radius andthe sheet thickness are selected as the design variables andequivalent draw-bead analyses are carried out with respect toeach design case constructed with the combination of the designfactors [8].

In this study, a stamping process of auto body has been designed to predict the stamping process and the sheet mechanical behavior.

\section{THE INFLUENCE OF THE PARAMETER ON THE STAMPING PROCESS}

In the actual stamping production, the effect of different parameters on the forming and stamping process forming member quality is very clear. Reasonable parameters can improve the uniformity of drawing deformation, reduce excessive demands on the material properties, thereby reducing production costs drawing parts [9].

\section{A. Friction and lubrication}

Since the forming process, the surface of the metal material in direct contact with the mold, and the interaction surface have a great force, so that the material have a great friction at the die surface. Also of the friction increases the needed of shaping force and tensile stress within the side wall of the workpiece, leading to the workpiece is easy to break, thus, lubrication plays a big effect on drawing . 


\section{B. $B H F$}

In the sheet metal deep drawing process usually requires clamping device generates sufficient friction resistance to increase tensile stress of the sheet, and control material flow and avoid wrinkling. In general, if the BHF is too small, it is difficult to have effectively control the flow of material, sheet wrinkle easily happend and if BHF is too large, although avoid wrinkling, but crack trend will be significantly increased. Meanwhile, the surface of the mold and the plate material also increases the possibility of damage, affect the die life and sheet metal deep drawing quality. Therefore, the size of BHF is an important process parameters in sheet metal forming, it is laso an important way to control the materail flow within the sheet.

\section{Drawbead}

Drawbead use in sheet metal deep drawing can be expected to strengthen the blankholder's ability to control the flow of material, by add feed resistance, so that the blank drawing have sufficient tensile stress, increase the stiffness of drawing parts and reduce the distorted, relaxation, ripple and shrinkage defects by the springback, generated to expand the adjustment range of BHF.

\section{Punch and Die Radius}

The size of the punch and die radius plays a big role to obtain the desired drawing. The two main defects of cover frawing parts of are wrinkling and cracking. When the punch radius is too small, drawing blank bending straight wall portion and the bottom of the transition zone increase, the strength of the dangerous section has been weakened, and when the recess die radius is too small, the tensile stress blank side walls of the respective force transmission zone increases, both of which will cause the drawing coefficient increases, increasing the deformation resistance of the sheet, causing lower die life and total drawing force increases. If the punch or die radius is too large, the sheet metal deformation resistance is small, the metal flow is good, but will be a corresponding reduction must change the effective area is small and the workpiece clamping, easy to wrinkle parts, so determining the punch fillet radiu must be considered together with the shape characteristics, drawbead and other factors .

\section{E. The Dimension of The Blank}

For some structural asymmetry of cover, since the deformation is not uniform when drawing, and thus the workpiece type cavity around the entire feed have different resistance, except teh control of drawbead and BHF parameters we also need to make appropriate trimming according to the formation characteristics before the deformation happen. Because too big flange will make the tensile stress increases, but at the same time will make the adjacent cavity prone to rupture. Conversely, when the flange edge is small, the tension stress is reduced, so that the the feed resistance $s$ atflange reduced, the material flows easily, but also easy to make the cavity adjacent to wrinkle. Therefor the dimension of the flanges directly affect the quality of drawing parts.

\section{F. Die Clearance}

The reliablity of the gap between the punch and die gap directly affect the quality of drawing parts, if adjusted unproperly, the large gap side, on the side wall drawing parts wrinkle easily, even in the periphery appear wavy.

\section{SIMULATION MESH AND DETAIL}

The auto body assembly is shown on the Fig. I. and Fig. II.

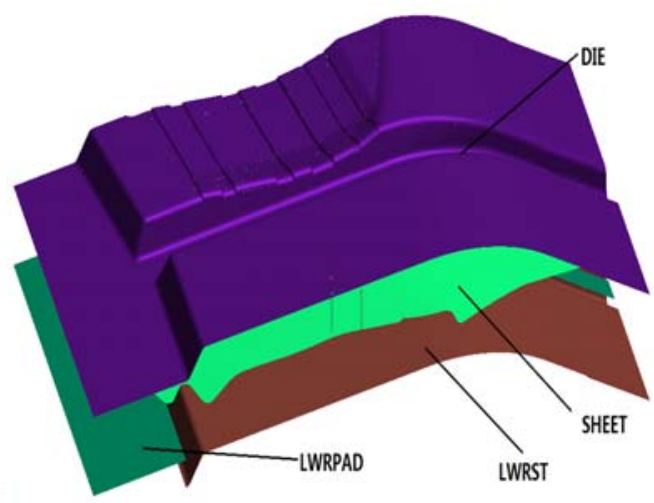

FIGURE I. THE ASSEMBLY OF THE STAMPING STAGE1

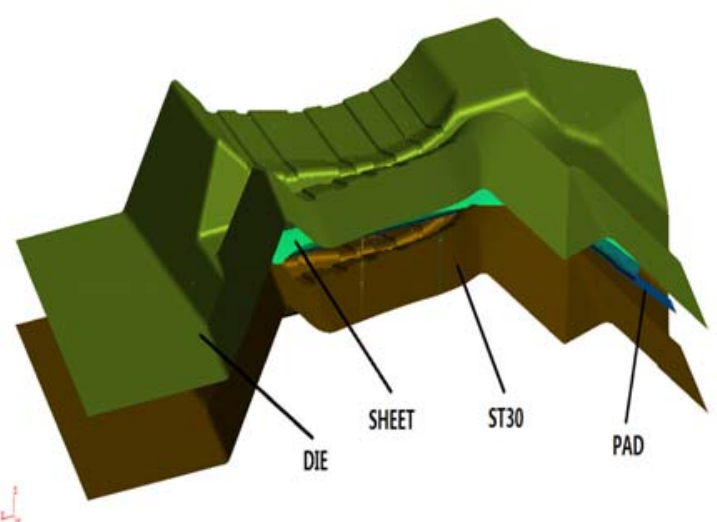

FIGURE II.THE ASSEMBLY OF THE STAMPING STAGE2

The material is SP151-590. The thickness of the blank is $2 \mathrm{~mm}$. Table I. shows the material mechanical properties.

TABLE I. MECHANICAL PROPERTIES OF SP151-590

\begin{tabular}{|l|l|l|l|l|l|l|}
\hline $\begin{array}{l}\text { Yield } \\
\text { stress } \\
\left(\mathrm{n} / \mathrm{mm}^{2}\right)\end{array}$ & $\begin{array}{l}\mathrm{n} \text { - } \\
\text { value }\end{array}$ & $\begin{array}{l}\text { Anisotropic } \\
\text { type }\end{array}$ & r 0 & r 45 & r 90 & $\begin{array}{l}\text { E-modulus } \\
(\mathrm{GPa})\end{array}$ \\
\hline 925 & $\begin{array}{l}0.11 \\
5\end{array}$ & Orthotropic & $\begin{array}{l}0.7 \\
4\end{array}$ & 0.74 & $\begin{array}{l}0.7 \\
4\end{array}$ & 210 \\
\hline
\end{tabular}

The friction coefficient in this simulation process is 0.19 and the holding force is $120.9 \mathrm{e}+5 \mathrm{~N}$. In the simulation process, there are two stages. The forming process has been divided into two processes.

\section{NUMERICAL RESULT AND DISCUSSION}

With the autoform software, we get the simulation results. The FLD is showed on the Fig. III. Which we can find that most points are are within the limitation which means the two result are allowable. But some elements are closed to the critical line which is dangerous and should be avoid in the pratice. 


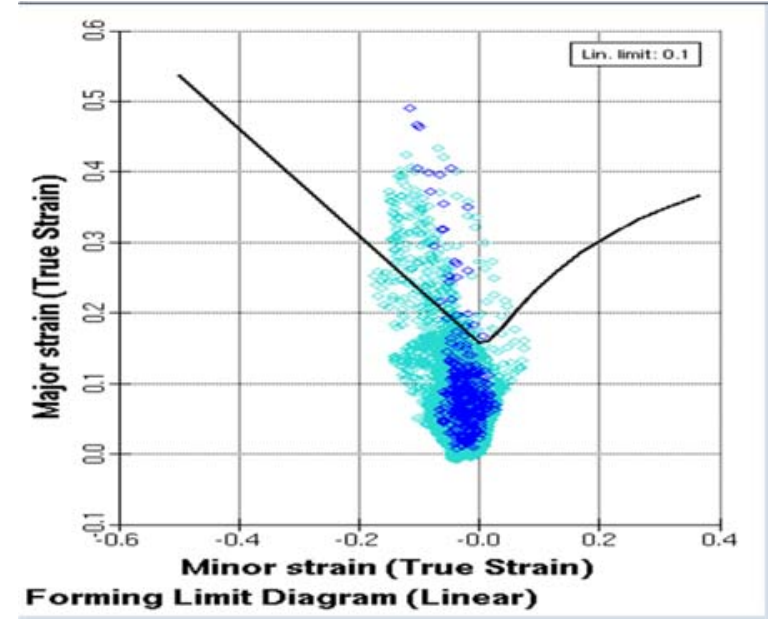

FIGURE III. THE FLD OF THE SHEET

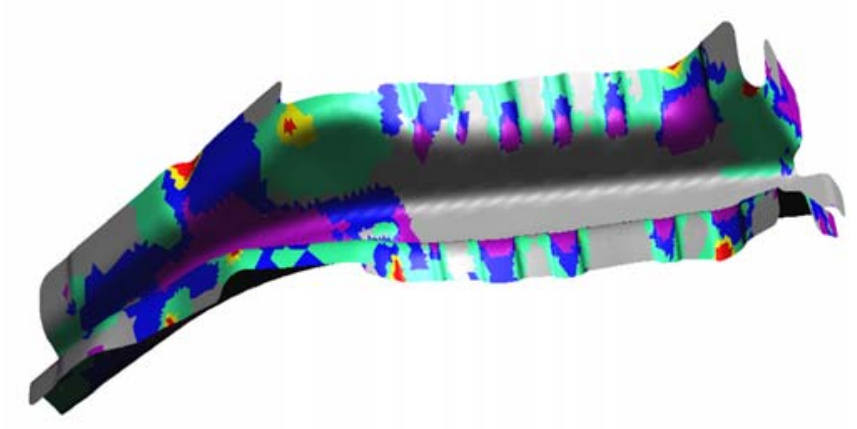

L.

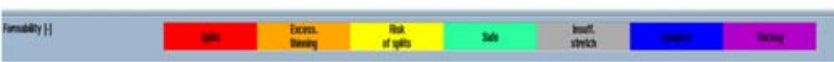

FIGURE IV. THE FORMABILITY OF THE SHEET

The formability of the simulations are showed on the Fig. IV. The result shows that compress and thicking is likely to occured at some region.

The plastic strain distribution of the sheet is shown on the Fig. V. The maximum strain in sheet is $0.9247 \mathrm{Mpa}$ and maximum strain is 0 . Fig. VI. shows the wrinkling tendency of the sheet .

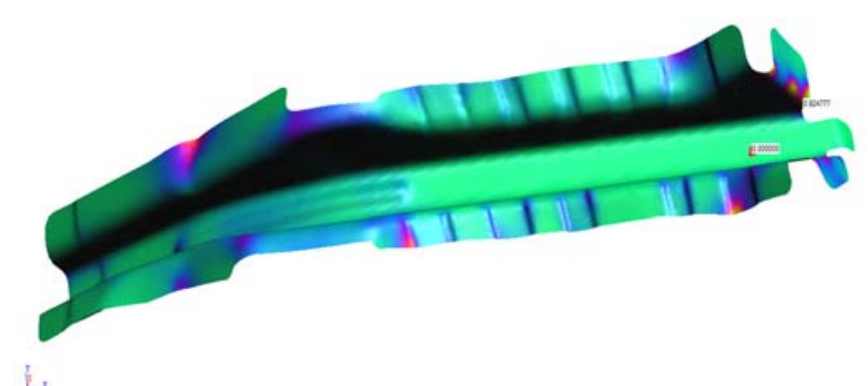

FIGURE V. THE DISTRIBUTION OF PLASTIC STRAIN

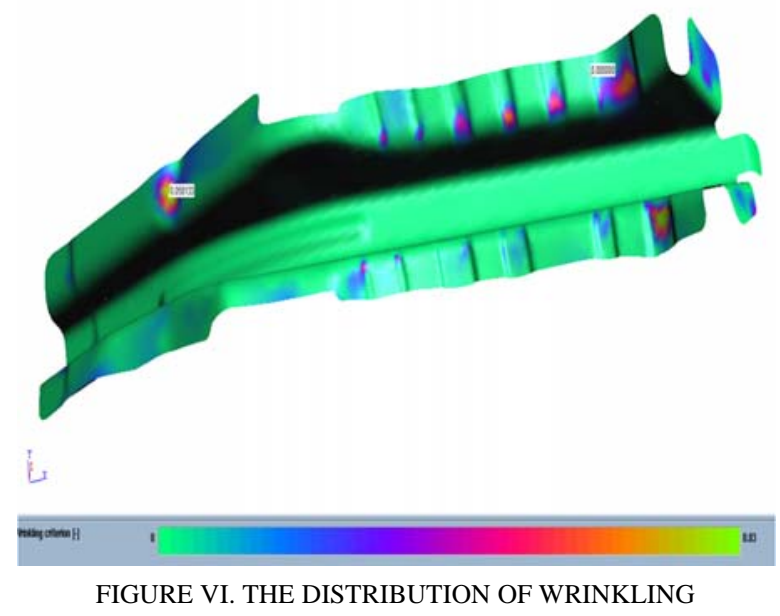

Fig.VII. shows the thickness distribution of the sheet. The minimum thickness is $1.3871 \mathrm{~mm}$. Which means the sheet have an $31 \%$ thinner than the original one. The maximum thickness is $2.1374 \mathrm{~mm}$.

The major strain distribution is shown on the Fig. VIII. According to the result, the maximum strain is 0.4909Mpa.
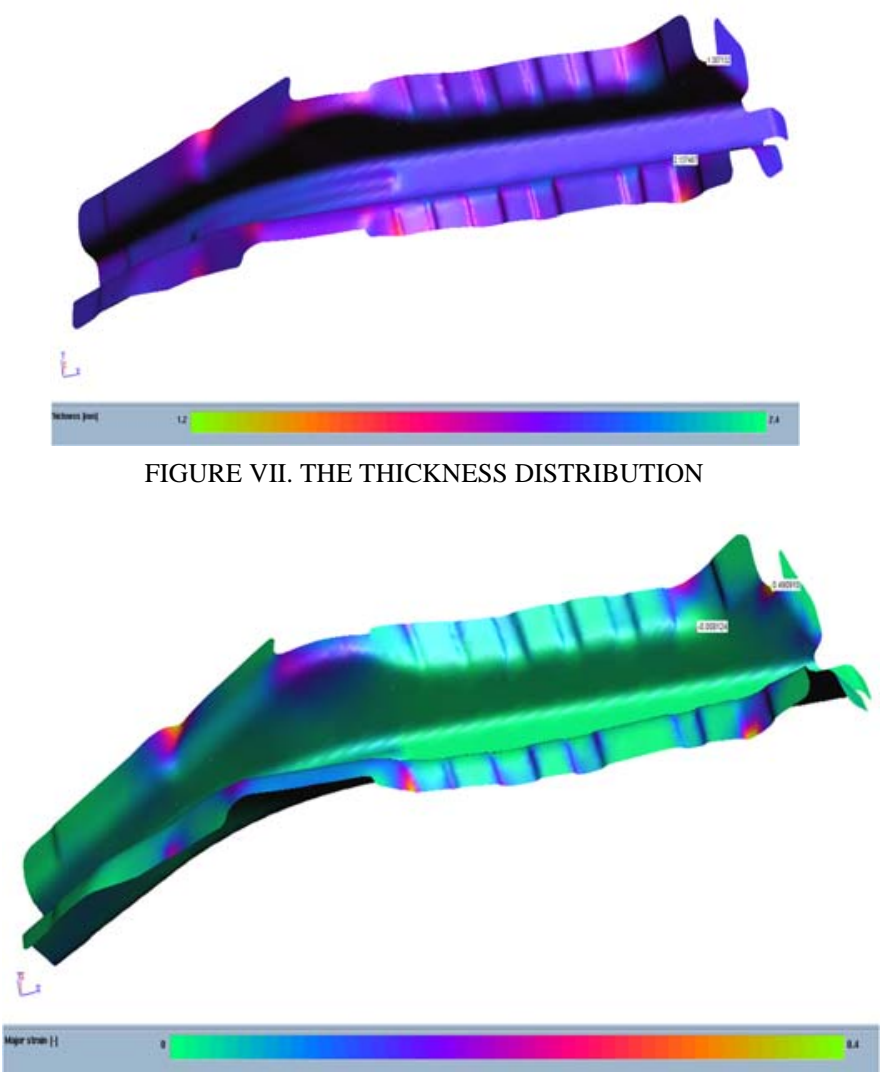

FIGURE VIII. THE MAJOR STRAIN DISTRIBUTION

\section{THE EXPERIMENT DETAILS}

The Fig. IX. and Fig. X. shows the dies of the multi-stage stamping process. 


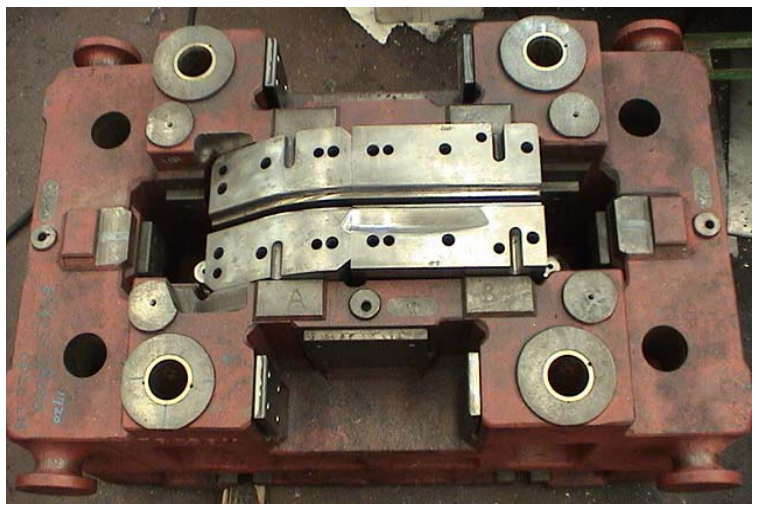

FIGURE IX.THE DIE OF THE STAMPING STAGE1

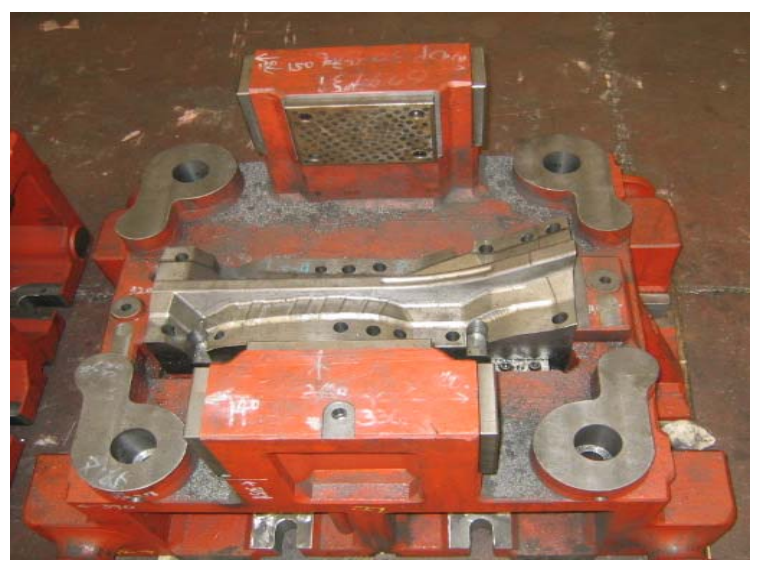

FIGURE X.THEDIE OF THE STAMPING STAGE2

Checking fixture has been a important way of quality control for the auto body manufacturing. An inadequate quality of the auto body stamping process not only affect the aesthetic value of the vehicle, but will also cause problems such as noise, variation and some other problems. So checking fixture is necessary for the auto body stamping process. The Fig. XI. has shown the checking fixture of the auto body product. The size of the part is $880 * 630 * 930 \mathrm{~mm}$. The weight of the part is 242.5lbs.

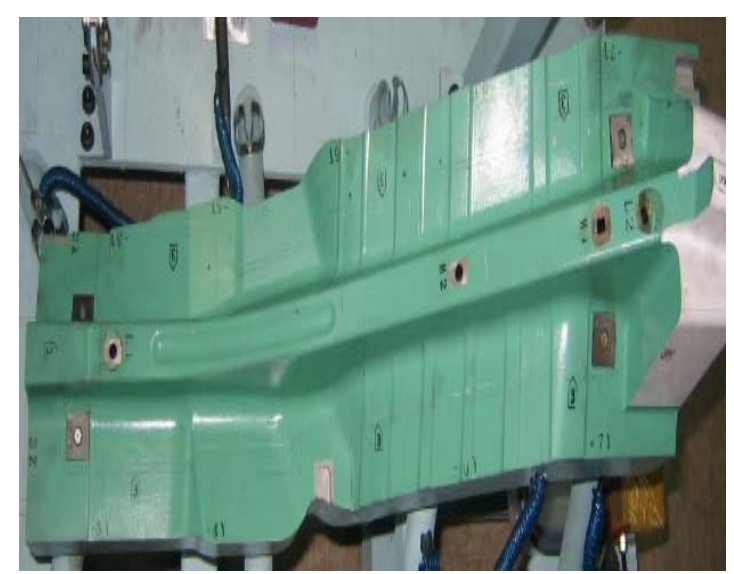

FIGRURE XI. THE CHECKING FIXTURE OF THE AUTO BODY PART

\section{CONCLUSIONS}

The autoform software offers a quickly and briefly simulation of the auto body sheet forming process. From the simulation result, we can evaluate and optimize the die design. With these simulations, we can conclude out that:

1. The FLD have been analyzed and it shows that the major strain is located under the target line. But there are still have some point out of the limitation.

2. The formability of the sheet shows that although the major regions of the sheet are safe, there are some small regions have the tendency to be wrinkling. Optimization should be applied to die to get a better result.

3. The thickness distribution of the auto body sheet has been elaborated in the simulation. The maximum thinning rate is $31 \%$.

\section{ACKNOWLEDGEMENT}

This research was financially supported by The Project Management Center Cultivating Smart Grid \& Clean Energy Manpower (CK-1), JNU.

\section{REFERENCES}

[1] M. Kawka, A. Makinouchi, Shell-element formulation in the static explicit FEM code for the simulation of sheet stamping, Journal of Material Processing Technology 50 (1995) 105-115.

[2] M. Kawka, A. Makinouchi, Shell-element formulation in the static explicit FEM code for the simulation of sheet stamping, Journal of Material Processing Technology 50 (1995) 105-115.

[3] S.B. Kim, H. Huh, Forming limit diagram of auto-body steel sheets for high-speed sheet metal forming, Journal of Material Processing Technology 211(2011) 851-862

[4] Nader Asna, On springback of double-curved auto body panels, International Journal of Mechanical Science 43(2001) 5-37

[5] Gunnar Ekstrand, Nader Asnafi, On testing of the stiffness and the dent resistance of auto body panels, Materials and Design 19(1998) 145-156

[6] Sergey F.Golovashchenko,A study on trimming of aluminum auto body sheet and development of a new robust process eliminating burrs and slivers, International Journal of Mechanical Science 48(2006) 1384-1400

[7] A. Anderssona, Evaluation and visualization of surface defects on auto-body panels, Journal of Material Processing Technology 209(2009) 821-837

[8] G.H. Bae, J.H. Song, Simulation-based prediction model of the draw-bead restraining force and its application to sheet metal forming process ,Journal of Material Processing Technology 187-188 (2007) 123-127

[9] Dong Hongzhi, Lin Zhongqin, Investigation of sheet metal forming by numerical simulation and experiment, Journal of Material Processing Technology 103(2000) 404-410 